\title{
The Effect of Ball Milling Time on the Isolation of Lignin in the Cell Wall of Different Biomass
}

\author{
Guangrong Yang ${ }^{1,2+}$, Xueying $\mathrm{An}^{3 \dagger}$ and Shilong Yang ${ }^{4 *}$ \\ ${ }^{1}$ College of Furniture and Industrial Design, Nanjing Forestry University, Nanjing, China, ${ }^{2}$ School of Landscape Architecture, \\ Jiangsu Vocational College of Agriculture and Forestry, Jurong, China, ${ }^{3}$ State Key Laboratory of Pharmaceutical Biotechnology, \\ Department of Sports Medicine and Adult Reconstructive Surgery, Nanjing Drum Tower Hospital, The Affiliated Hospital of \\ Nanjing University Medical School, Nanjing, China, ${ }^{4}$ Advanced Analysis and Testing Center, Nanjing Forestry University, Nanjing, \\ China
}

Ball milling technology is the classical technology to isolate representative lignin in the cell wall of biomass for further investigation. In this work, different ball milling times were carried out on hardwood (poplar sawdust), softwood (larch sawdust), and gramineous material (bamboo residues) to understand the optimum condition to isolate the representative milled wood lignin (MVL) in these different biomass species. Results showed that prolonging ball milling time from 3 to $7 \mathrm{~h}$ obviously increased the isolation yields of MWL in bamboo residues (from $39.2 \%$ to $53.9 \%$ ) and poplar sawdust (from $15.5 \%$ to $35.6 \%$ ), while only a slight increase was found for the MWL yield of larch sawdust (from $23.4 \%$ to $25.8 \%$ ). Importantly, the lignin substructure of $B-\mathrm{O}-4$ in the MWL samples from different biomasses can be a little degraded with the increasing ball milling time, resulting in the prepared MWL with lower molecular weight and higher content of hydroxyl groups. Based on the isolation yield and structure features, milling time with 3 and $7 \mathrm{~h}$ were sufficient to isolate the representative lignin (with yield over 30\%) in the cell wall of bamboo residues and poplar sawdust, respectively, while more than $7 \mathrm{~h}$ should be carried out to isolate the representative lignin in larch sawdust.

${ }^{+}$These authors have contributed equally to this work and share first authorship

Specialty section:

This article was submitted to Bioprocess Engineering, a section of the journal Frontiers in Bioengineering and Biotechnology

Received: 02 November 2021 Accepted: 15 November 2021

Published: 14 December 2021

Citation:

Yang G, An X and Yang S (2021) The Effect of Ball Milling Time on the Isolation of Lignin in the Cell Wall of Different Biomass.

Front. Bioeng. Biotechnol. 9:807625. doi: 10.3389/fbioe.2021.807625
Keywords: biomass, milled wood lignin, $\beta-0-4$, molecular weight, functional group

\section{INTRODUCTION}

As the depletion of fossil energy and its derived environment issues, a sustainable alternative program is sought urgently. Lignocellulosic biomass is regarded as a clean and renewable resource and shows potential to replace petrochemicals to produce biochemicals, biopolymers, biofuels, etc. (Himmel et al., 2007; Pei et al., 2020; Lin et al., 2021; Zhao et al., 2021a). Hence, developing lignocellulosic biomass to produce green energy and biomaterials is the main concern of scientists in this century. All of lignocellulosic biomass is composed of the cellulose, hemicellulose, and lignin with different proportions (Hu et al., 2021; Zhang et al., 2021; Zhao et al., 2021b). Currently, the application of cellulose and hemicellulose have been much investigated and converted into energy chemicals in industry (Huang et al., 2016a; Chen et al., 2018; Lai et al., 2019; Luo et al., 2021). However, lignin, the major phenolic polymers in biomass, remains underutilized in biorefining, which is required to explore the potential applications in theory (Liu et al., 2021a; Liu et al., 2021b; Huang et al., 2022). Actually, many works have shown that lignin possesses the potential to be further converted into different chemicals and materials, such as phenolic resins, dispersants, binders, 
carbon fibers, and active substance (Ragauskas et al., 2006; Yang et al., 2007; Jiang et al., 2017a; Zheng et al., 2021a). In addition, lignin is composed of cross-linked phenylpropanoid units, including $p$-hydroxyphenyl $(\mathrm{H})$, guaiacyl $(\mathrm{G})$, and syringyl $(\mathrm{S})$. In the network of lignin biomacromolecule, both of these units are linked by inter-unit linkages of carbon-carbon $(\beta-\beta, \beta-5, \beta-1$, and $\left.5-5^{\prime}\right)$ and ether bonds $\left(\beta-\mathrm{O}-4^{\prime}, a-\mathrm{O}-4^{\prime}\right.$, and 5-O-4 $)$ (MartínSampedro et al., 2019). Therefore, due to the highly variable complex structure of lignin, how to effectively separate lignin from lignocellulosic biomass is the key to efficient utilization of lignin (Yuan et al., 2013).

Now, a variety of extraction methods has been reported to isolate the lignin in biomass. Generally, the extraction methods can be divided according to the used solvent, such as alkaline lignin, lignosulfonate, organic solvent lignin, milled wood lignin (MWL), Klason lignin, and cellulolytic enzyme lignin (Lange et al., 2013; Huang et al., 2017b; Huang et al., 2018; Yun et al., 2021). Different types of lignin show different characterizations of lignin. Even though these methods have been proposed, there are still some issues. For example, the structures of lignin can be severely degraded during alkaline extraction process (alkaline lignin and organic solvent lignin) and condensed during acid hydrolysis process (Klason lignin) (Yuan et al., 2010; Sun et al., 2013; Jiang et al., 2020). For cellulolytic enzyme lignin, a lot of enzymes should be used to degrade the carbohydrate that linked to lignin, and the obtained lignin sample still possesses a high amount of carbohydrate (Guerra et al., 2006). Currently, MWL is considered as the most comprehensive method of keeping nativelike lignin structure from biomass (Zhang et al., 2010). The MWL separation method was proposed by Bjorkman in 1956, which uses the solvent of dioxane/water to extract the sufficient milled lignocellulosic biomass (Bjorkman, 1956). It has been reported that the structure of MWL has only minor changes occurring during the extraction process of lignin, which is very fit with the lignin structure in the original biomass. However, the extraction method of MWL also has unexpected problems in practical application of yields of lignin, which is dependent on the ball milling time (Wang et al., 2019; Wang R. et al., 2021). Therefore, this method is only widely used in theoretical research, contributed to provide more accurate theoretical foundations for industrialized applications of lignin. Technologically, ball milling should be carried out to isolate MWL from biomass. However, due to the diversified and complex cell structure of biomass, different ball milling time should be carried out to isolate the representative MWL from different biomass.

Technologically, many advanced technologies have been investigated to characterize the structure of lignin, such as gel permeation chromatography (GPC), Fourier transform infrared spectroscopy (FTIR), nuclear magnetic resonance technology (NMR), etc. (Huang et al., 2017a; Xu et al., 2011; Zhang et al., 2010; Martín-Sampedro et al., 2019). NMR is a state-of-the-art analytical technique that can be applied to analyze the structural features of the lignin samples from different biomasses (Liao et al., 2020). The NMR technology is considered to be nondestructive technology for lignin during analysis process, which is able to detect different nuclei of the different linkages in lignin. Meanwhile, NMR is a structure-sensitive analysis technology, which can get the structural information of lignin in solution phase and solid phase (Liao et al., 2020; Halleraker and Barth., 2020; Zhao et al., 2021a). Hence, the application of NMR technology to analyze the structure of lignin can provide detailed and comprehensive information about them (Luykx et al., 2008). Specifically, the ${ }^{1} \mathrm{H}$ NMR spectroscopy can get the hydrogen (proton) signal information of lignin, which can be subdivided into different structural regions (Azhar et al., 2007). The quantitative methods of ${ }^{13} \mathrm{C}$ NMR spectroscopy can measure the carbon signals at different categories of $\mathrm{C}$ structures in lignin (Capanema et al., 2004). Meanwhile, 2D heteronuclear single quantum coherence (HSQC) NMR technology has also been developed to get the quantitative information of lignin structures, including lignin aliphatic and aromatic areas (Ibrahim et al., 2012; Tang et al., 2021). In addition, ${ }^{31} \mathrm{P}$ NMR spectroscopy has also been widely used to quantify the functional groups (hydroxyl and the carboxyl groups) of lignin (Hussin et al., 2014). Overall, with the scientific research of this century focused on the comprehensive utilization of lignin, the NMR is considered to be an important lignin structure analysis technology.

Even the influence of ball milling on the efficiency of MWL isolation and structure has been substantially studied. There is no comparative work showing how the structure of MWL samples from different biomass species changes by ball milling at the same milling time. In this work, different ball milling times of 3-7 h were carried out for different biomass of bamboo residues, poplar sawdust, and larch sawdust. This is aimed to provide an appropriate protocol to obtain the representative MWL for further application. To understand the effect of ball milling time on the structure of prepared MWL samples, the chemical composition, molecular weight, lignin substructure, and content of functional groups were analyzed by high-performance liquid chromatography (HPLC), gel permeation chromatography (GPC), 2D-HSQC nuclear magnetic resonance (NMR), and quantitative ${ }^{31} \mathrm{P}$ NMR, respectively.

\section{MATERIALS AND METHODS}

\section{Materials}

The moso bamboo residues, poplar sawdust, and larch sawdust were collected from the furniture process factory in Fujian, China. Before the analysis of the major components in all sawdust, they were ground into particles with the size of $2-5 \mathrm{~mm}$ and then extracted by benzene/ethanol $(2: 1, \mathrm{v} / \mathrm{v})$ for $16 \mathrm{~h}$ to remove the solvent extractives. The major components of the bamboo residues, poplar sawdust, and larch sawdust were $43.5 \%$, $46.6 \%$, and $41.8 \%$ of glucan, $19.5 \%, 19.8 \%$, and $21.7 \%$ of xylan, and $35.4 \%, 28.3 \%$, and $29.4 \%$ of lignin, respectively.

\section{Isolation and purification of lignin from different biomasses}

The lignins in the biomass of bamboo residues, poplar sawdust, and larch sawdust were isolated according to the standard method proposed by Bjorkman (1956). Specifically, $10 \mathrm{~g}$ of 
wood sawdust particle was loaded in a $100-\mathrm{ml} \mathrm{ZrO}_{2}$ bowl with 25 $\mathrm{ZrO}_{2}$ balls $(\Phi \mathrm{A}=1 \mathrm{~cm})$. Then the particle was milled by the planetary ball milling under a rotation speed of $600 \mathrm{rpm}$ for a total effective time of 3,5, and $7 \mathrm{~h}$. During milling process, a milling time of $10 \mathrm{~min}$ and a pause time of $15 \mathrm{~min}$ were carried out for the planetary ball milling instrument. After milling, all ball-milled meals were collected to extract the lignin using a mixture of 1,4-dioxane and water $(96: 4, \mathrm{v} / \mathrm{v})$ with a liquid-to-solid ratio of $20: 1$ for $24 \mathrm{~h}$. The extraction process was repeated three times with a fresh mixture of 1,4-dioxane and water. After three times of extraction, all filtrates were mixed and evaporated by vacuum rotary evaporation at $45^{\circ} \mathrm{C}$ to get the crude lignin solid, which was termed as milled wood lignin (MWL). To purify the crude MWL, the solid was dissolved in a mixture of acetic acid and water $(90: 10, \mathrm{v} / \mathrm{v})$ with a liquid-to-solid ratio of 20:1 (ml:g). Then the dissolved lignin in the mixtures was precipitated by adding distilled water. The precipitated MWL was washed with water several times and freeze dried to get the solid. The dried MWL solid was dissolved in a mixture of dichloroethane and ethanol $(2: 1, \mathrm{v} / \mathrm{v})$ with a liquid-to-solid ratio of $10: 1$ and then precipitated by adding ether $(10 \mathrm{ml} / \mathrm{ml}$ of dichloroethane/ ethanol). The precipitated MWL was sequentially washed by ether and petroleum and then air dried to obtain the purified MWL.

\section{Component analysis of biomasses and prepared lignins}

The major components of three sawdust and the purified MWL preparations were measured according to the standard procedure proposed by the National Renewable Energy Laboratory (NREL) (Sluiter et al., 2011). Specifically, $30 \mathrm{mg}$ of extractive-free sawdust particles (20-40 mesh) or MWL powder was hydrolyzed by $0.3 \mathrm{ml}$ of $72 \% \mathrm{H}_{2} \mathrm{SO}_{4}$ at $25^{\circ} \mathrm{C}$ for $1 \mathrm{~h}$. The hydrolyzed substrate by $72 \% \mathrm{H}_{2} \mathrm{SO}_{4}$ was diluted to $4 \% \mathrm{H}_{2} \mathrm{SO}_{4}$ with distilled water and auto-hydrolyzed at $121^{\circ} \mathrm{C}$ for $1 \mathrm{~h}$. The sugar contents in the acid-hydrolyzate were analyzed by high-performance liquid chromatography (HPLC, Agilent 1,260), which is equipped with HPX-87H column and refractive index (RI) detector. The acid-soluble lignin in the acid-hydrolyzate was determined by the ultraviolet spectrophotometer at $205 \mathrm{~nm}$. The acid-insoluble lignin was determined by weighting the residual solid (oven dried) in the acid-hydrolyzate. The lignin content in three sawdust and the purified MWL preparations was referred to the total amount of acid-soluble lignin and acid-insoluble lignin.

\section{Molecular weight analysis of prepared lignins}

The molecular weight determination for the prepared lignins was carried out by gel permeation chromatography (GPC). In order to improve the dissolving capacity of lignin in the tetrahydrofuran for GPC analysis, all MWL samples were acetylated according to the work of Pan (2008). For analysis, $2 \mathrm{mg}$ of acetylated lignin was dissolved in $2 \mathrm{ml}$ of tetrahydrofuran and ejected into the GPC system, which is equipped with a PL-gel $10 \mathrm{~mm}$ mixed-B $7.5 \mathrm{~mm}$ i.d. column and an ultraviolet detector. The analysis was performed at ambient temperature using tetrahydrofuran as the eluent $(1 \mathrm{ml} / \mathrm{min})$. Monodisperse polystyrene was used as the standard to calibrate the molecular weight of lignin in the GPC system.

\section{D-HSQC nuclear magnetic resonance analysis of prepared lignins}

To get the information of the substructure of lignins from different biomasses under various milling times, 2D-HSQC NMR analysis was carried out using a Bruker AVANCE $600 \mathrm{MHz}$ NMR spectrometer equipped with a 5-mm BBO probe. For analysis, $100 \mathrm{mg}$ of oven-dried lignin was dissolved in $400 \mu$ of DMSO- $\mathrm{d}_{6}$ and then transferred into an NMR tube. The acquisition data points for F2 $(1 \mathrm{H})$ dimension and F2 (13C) dimension were $1,024(53 \mathrm{~ms})$ and 256 data points $(5.14 \mathrm{~ms})$, respectively. The total delay time and scan times were $1.5 \mathrm{~s}$ and 160 for the acquisition process, respectively. The 2D-HSQC NMR spectra were processed using the TopSpin software (4.0.5 version).

\section{Functional groups analysis of prepared lignins}

Quantitative ${ }^{31} \mathrm{P}$ NMR was carried out to analyze the functional groups using the NMR spectrometer (the same as 2D-HSQC NMR analysis). For analysis, $0.04 \mathrm{~g}$ of oven dried lignin and $0.5 \mathrm{ml}$ of anhydrous pyridine/ $\mathrm{CDCl}_{3}$ mixture (1.6:1, v/v) were introduced into the NMR tube to dissolve the lignin. Then $0.2 \mathrm{ml}$ of internal standard solution (endo-N-hydroxy-5-norbornene-2, 3 -dicarboximide, $9.23 \mathrm{~g} / \mathrm{L}$ ), $0.05 \mathrm{ml}$ of relaxation reagent solution (chromium (III) acetylacetonate, $5.6 \mathrm{~g} / \mathrm{L}$ ) and $0.1 \mathrm{ml}$ of phosphitylating reagent solution (2-chloro-4,4,5,5-tetramethyl1,2,3-dioxaphospholane) were sequentially added into the NMR tube for analysis. The acquisition parameters for ${ }^{31} \mathrm{P} N M R$ analysis were according to the standard protocol in NMR spectrometer.

\section{RESULTS AND DISCUSSION}

\section{Effect of different milling times on the isolation yield and chemical composition of lignin from different biomass}

As the balling milling is the first step to isolate the MWL sample as the native-like lignin in wood and different pretreated wood, it is important to understand how the milling time affects the isolation yield and structural changes of lignin in different woods. In this work, ball milling with 3,5 , and $7 \mathrm{~h}$ were performed on the different biomass (bamboo residues, poplar sawdust, and larch sawdust) to isolate the native-like lignin, which is aimed to provide an appropriate protocol to obtain the representative lignin for further application. In Table 1, it can be seen that the isolation yields of each MWL sample from different biomass were linearly increased with the milling time from 3 to $7 \mathrm{~h}$. These results were in accordance with the work of 
TABLE 1 | The isolation yield and composition content of prepared milled wood lignin (MWL) samples from different biomass with different milling times.

\begin{tabular}{|c|c|c|c|c|c|c|c|}
\hline \multirow[t]{2}{*}{ Biomass } & \multirow[t]{2}{*}{ Milling time (h) } & \multirow{2}{*}{$\begin{array}{l}\text { Isolation yield of MWL } \\
(\%)\end{array}$} & \multicolumn{5}{|c|}{ Composition content of MWL (\%) } \\
\hline & & & Xylan & Arabinan & Glucan & Mannan & Lignin \\
\hline \multirow[t]{3}{*}{ Bamboo residues } & 3 & 39.2 & 4.9 & 1.1 & 0.8 & I & 91.5 \\
\hline & 5 & 45.7 & 4.9 & 0.8 & 0.6 & I & 92.8 \\
\hline & 7 & 53.9 & 3.6 & 0.8 & 0.6 & / & 94.6 \\
\hline \multirow[t]{3}{*}{ Poplar sawdust } & 3 & 15.5 & 5.8 & 0.9 & 0.2 & / & 90.5 \\
\hline & 5 & 24.3 & 6.5 & 0.7 & 0.5 & / & 92.4 \\
\hline & 7 & 35.6 & 5.6 & 0.6 & 0.3 & / & 92.8 \\
\hline \multirow[t]{3}{*}{ Larch sawdust } & 3 & 23.4 & / & I & 2.8 & 6.8 & 90.1 \\
\hline & 5 & 24.8 & I & I & 1.1 & 5.6 & 92.1 \\
\hline & 7 & 25.8 & I & / & 1.0 & 5.4 & 92.9 \\
\hline
\end{tabular}

Capanema et al. (2015), who reported that the MWL yields of birch and maple could be enhanced from $8 \%$ to $28 \%$ and from $12 \%$ to $30 \%$ with an increased milling time from 2.5 to $10 \mathrm{~h}$, respectively, while it should be pointed out that there are some differences in the isolation yields of MWL (based on the Klason lignin in biomass) from bamboo residues, poplar sawdust, larch sawdust, which were in the range of $39.2 \%-53.9 \%, 15.5 \%-35.6 \%$, and $23.4 \%-25.8 \%$, respectively. It is reported that MWL preparation isolated from biomass with a yield over $30 \%$ can be regarded as the representative lignin in cell wall (Huang et al., 2016a). Hence, the results showed that milling times with 3 and $7 \mathrm{~h}$ were sufficient to isolate the representative lignin in the cell wall of bamboo residues and poplar sawdust, respectively, while, more than $7 \mathrm{~h}$ should be carried out to isolate the representative lignin in larch sawdust. This might be due to the more tough cell structure of larch than that of bamboo and poplar.

For the isolated lignin from the cell wall of biomass, the residual carbohydrate in the MWL preparation can affect its dissolving capacity in the DMSO- $\mathrm{d}_{6}$ for further analysis by NMR technology. Hence, the composition content of all prepared MWL samples were analyzed and shown in Table 1. From Table 1, it can be seen that both MWL preparations from bamboo residues, poplar sawdust, and larch sawdust contained carbohydrates of $5.0 \%-6.8 \%, 6.5 \%-7.7 \%$, and $6.4 \%-9.6 \%$, respectively. For the existing carbohydrates in MWL preparations, xylan was the major carbohydrate in MWL preparations from bamboo residues and poplar sawdust, while mannan was the major carbohydrate in MWL preparations from larch sawdust, which was due to their different biomass species. In this work, all the
MWL preparations were obtained from the crude lignin, and after tedious purification procedures, there are still some carbohydrates in the MWL preparations. This can be explained by the hemicellulose, which is covalently linked to lignin by phenyl glycoside linkages (PhGlc), benzyl ethers (BE), and -esters (Est), which is termed as lignin-carbohydrate complexes (LCC) (Zheng et al., 2021b; Gu et al., 2021). Technically, the existing LCC in the cell wall of biomass can be degraded during the milling process, while it is hard to remove during the purification process by various solvents, which can be the reason why the prepared MWL samples from different biomass cannot reach to a purity of $100 \%$ (Henriksson, 2017). Overall, the obtained MWL preparations from bamboo residues, poplar sawdust, and larch sawdust contained over $90 \%$ of lignin.

\section{Molecular weight analysis of prepared milled wood lignin samples}

To verify how the milling time affects the prepared MWL samples in bamboo residues, poplar sawdust, and larch sawdust by different milling times, the weight average molecular weight $\left(\mathrm{M}_{\mathrm{w}}\right)$ and number average molecular weight $\left(\mathrm{M}_{\mathrm{n}}\right)$ were analyzed and are shown in Table 2 . It can be seen that the $M_{w}$ values of the prepared MWL sample bamboo residues, poplar sawdust, and larch sawdust decreased from 8,577 to 5,324, 6,509 to, and 16,296 to $13,345 \mathrm{~g} / \mathrm{mol}$, respectively, when the milling increased from 3 to $7 \mathrm{~h}$. These results indicated that the increased milling time can decrease the molecular weight of prepared MWL from biomass. In the work of Guerra et al. (2006) and Wang R.

TABLE 2 | The molecular weight of prepared MWL samples from biomass at different milling times.

\begin{tabular}{|c|c|c|c|c|}
\hline \multirow[t]{2}{*}{ Biomass } & \multirow[t]{2}{*}{ Milling time (h) } & \multicolumn{2}{|c|}{ Molecular weight $(\mathrm{g} / \mathrm{mol})$} & \multirow[t]{2}{*}{ Polydispersity index (PDI) } \\
\hline & & Weight average $\left(M_{w}\right)$ & Number average $\left(M_{n}\right)$ & \\
\hline \multirow[t]{2}{*}{ Bamboo residues } & 3 & 8,577 & 4,754 & 1.80 \\
\hline & 7 & 5,324 & 2,816 & 1.89 \\
\hline \multirow[t]{3}{*}{ Poplar sawdust } & 3 & 6,509 & 3,430 & 1.90 \\
\hline & 5 & 6,337 & 3,214 & 1.97 \\
\hline & 7 & 4,330 & 2,436 & 1.78 \\
\hline & 7 & 13,345 & 4,848 & 2.75 \\
\hline
\end{tabular}




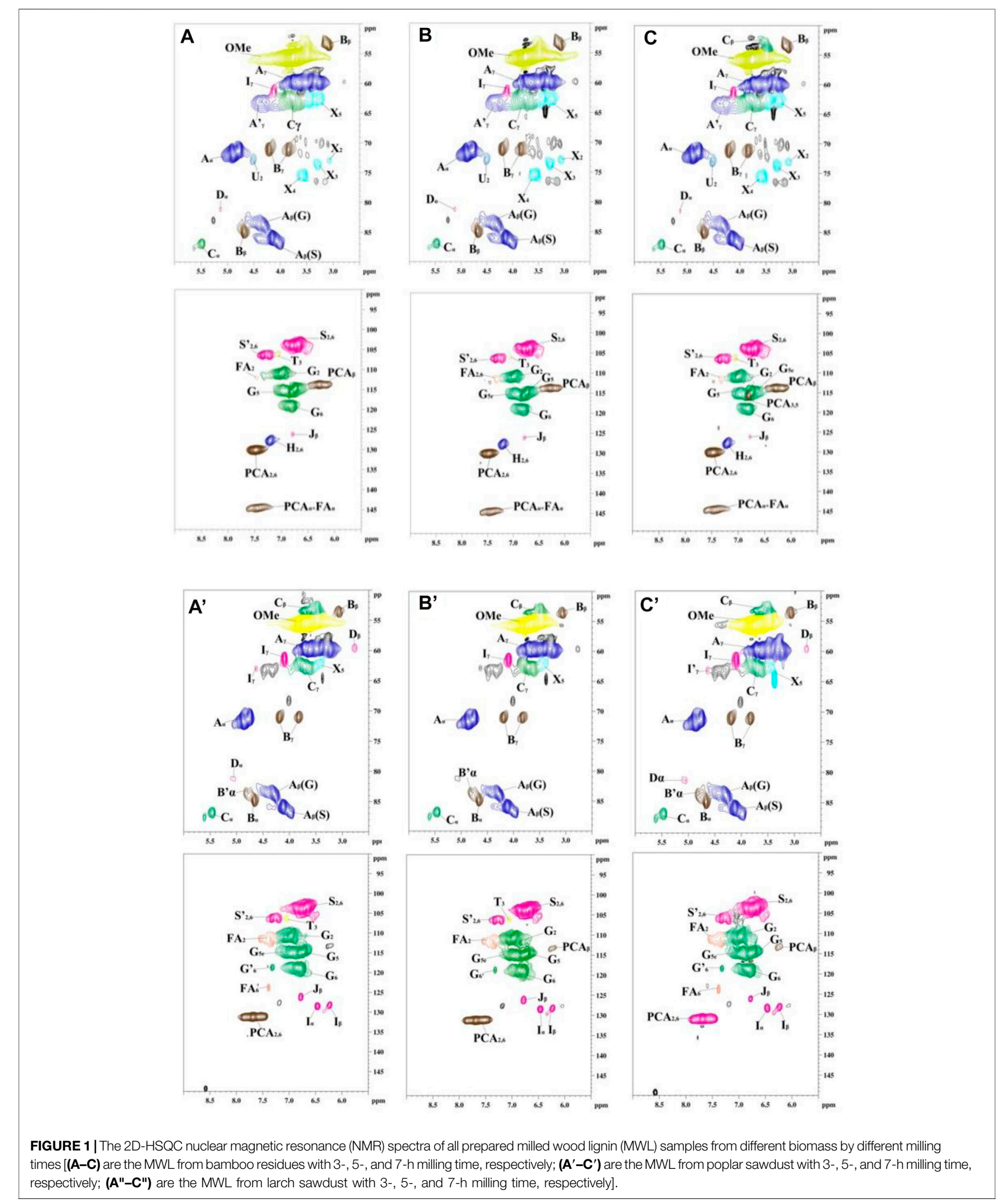




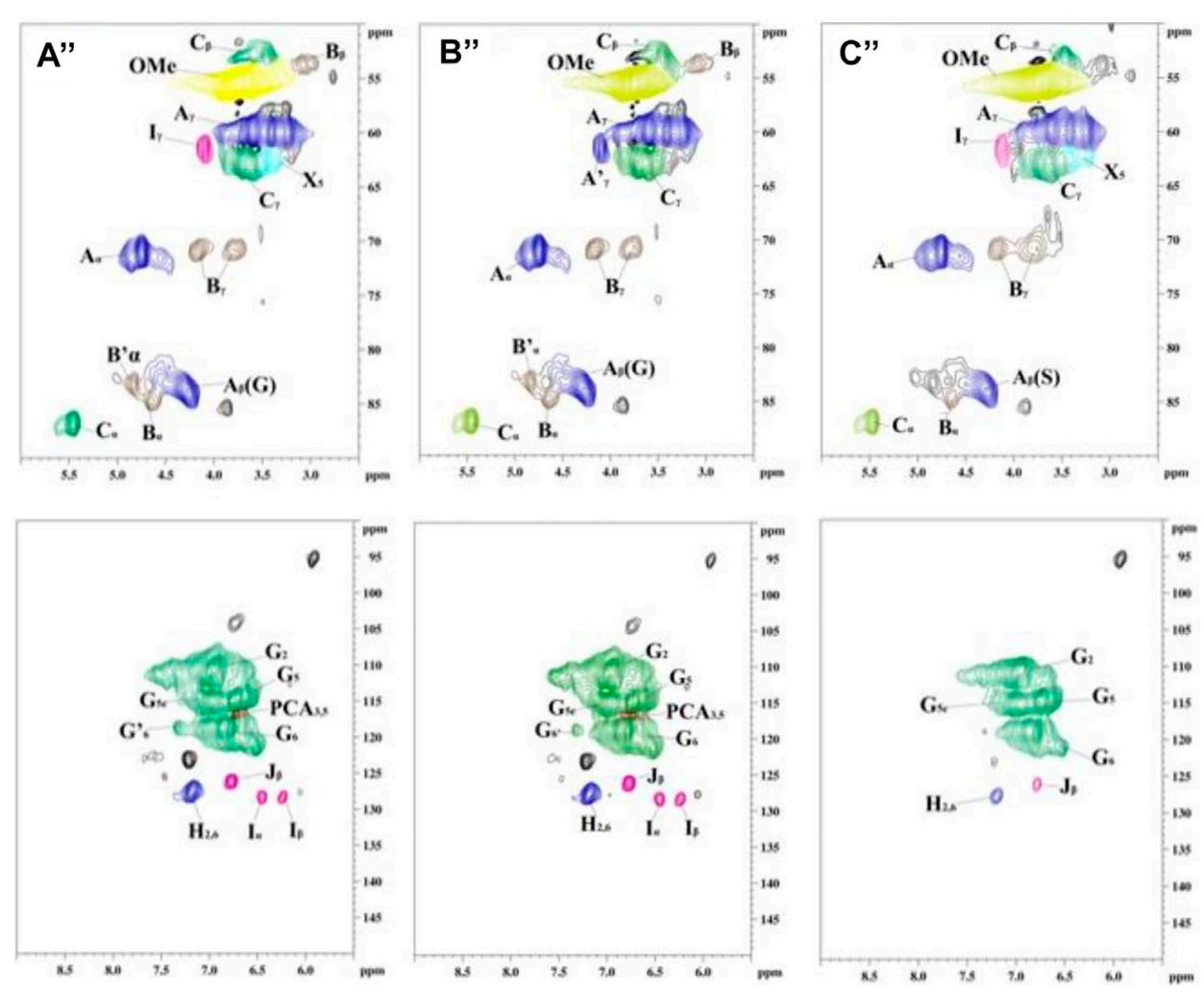

FIGURE 1 | (Continued)

et al. (2021), it was also reported that the intensive milling time can show the performance by decreasing the molecular weight of lignin in the cell wall of different biomass. In addition, Table 2 shows that both of the prepared MWL samples from different milling times possessed PDI values lower than 3, indicating that the isolated MWL samples possessed a relative homogeneousness (Kim et al., 2011; Huang et al., 2016b).

\section{Effect of different milling times on the structure of prepared milled wood lignin samples}

To indepthly elucidate the structure features of MWL samples in bamboo residues, poplar sawdust, and larch sawdust by different milling times, 2D-HSQC NMR analysis was carried out by dissolving lignin in DMSO- $\mathrm{d}_{6}$. The obtained NMR spectra of all MWL samples and the main structure diagram of lignin substructures in the spectra are shown in Figures $\mathbf{1}$ and 2, respectively.

In the side-chain $\left(\delta_{\mathrm{C}} / \delta_{\mathrm{H}} \quad 90-50 / 6.0-2.5\right)$ spectra, the substructures of $\beta-O-4(A), \beta-\beta$ (B), and $\beta-5$ (C) in all MWL samples can be clearly observed by identifying their corresponding C-H correlation signals (Jiang et al., 2017b; Huang et al., 2020; Wang R. et al., 2021; Wang Z. et al., 2021). In addition, the lignin units of syringyl units (S), guaiacyl units $(\mathrm{G})$, or p-hydroxyphenyl units $(\mathrm{H})$ can also be observed in the aromatic region $\left(\delta_{\mathrm{C}} / \delta_{\mathrm{H}} 135-100 / 8.5-5.5\right)$ spectra of MWL samples with some differences (Dong et al., 2020; Wang R. et al., 2021). Specifically, the S, G, and $H$ units can be found in the MWL spectra of bamboo residues, while only S/G units and G/H units existed in the MWL spectra of poplar sawdust and larch sawdust, respectively. Overall, the results indicated that increasing the ball milling time with different times did not show the performance in changing the phenylpropane structure of lignin units in all MWL samples, which is in accordance with the work of Huang et al. (2011).

It should be pointed out that only the overview of the presented lignin substructures in MWL samples can be obtained in Figure 1, which cannot provide the quantitative changes in each substructure. Hence, the amount of lignin substructures in MWL samples from different biomass were semiquantitatively calculated according to their signal clusters in 2D-HSQC spectra. The results were expressed based on 100 aromatic rings (100Ar) and are shown in Table 3. Table 3 shows that a decreased trend was observed for the amount of $\beta-O-4$ in MWL samples of different biomass treated by increased ball milling time. Specifically, the amount $\beta-\mathrm{O}-4$ in $\mathrm{MWL}$ of bamboo residues, poplar sawdust, and larch sawdust were decreased from 68.2/100Ar to 60.1/100Ar, from 58.7/100Ar to $55.5 / 100 \mathrm{Ar}$, and from $66.0 / 100 \mathrm{Ar}$ to $59.4 / 100 \mathrm{Ar}$, respectively, when the ball milling time was prolonged from 3 to $7 \mathrm{~h}$. In the work of Wang R. et al. (2021), they also found that the increased 
<smiles>CCCCOc1c(OC)cc(C(O)C(CO)Oc2c(OC)cc(C(C)(F)F)cc2OC)cc1OC</smiles>

A<smiles>CCOc1ccc(C(C)C(C)C)cc1</smiles>

H<smiles>CCOc1c(OC)cc(C(C)C(C)O)cc1OC</smiles>

S<smiles>COCC1C(c2cc(O)c(O)c(OC)c2)COC1c1cc(O)c(O)cc1O</smiles>

B<smiles>CCOc1ccc(C(C)C)cc1OC</smiles>

G<smiles>CCOc1c(OC)cc(C2Oc3c(OC)cc(C(C)C)cc3C2CO)cc1OC</smiles>

C<smiles>CCOC(=O)/C=C/c1ccc(OCC)c(OC)c1</smiles>

FA<smiles>CCOC(=O)/C=C/c1ccc(OCC)cc1</smiles>

PCA

FIGURE 2 | The structure diagram of lignin substructures in the spectra [(A): $\beta-O-4 ;(\mathbf{B})$ : $\beta-\beta ;$ (C): $\beta-1 ; H$, p-hydroxyphenyl units; $S$, syringyl units; G, guaiacyl units; FA, ferulate; PCA, p-coumarate).

ball milling time indeed showed a performance in degrading the $\beta-\mathrm{O}-4$ in the isolated lignin from different biomass, resulting in a decreased amount, while the amount of $\beta-\beta$ in MWL samples were increased when prolonging the ball milling time, indicating it is more recalcitrant than $\beta-\mathrm{O}-4$ to be degraded during ball milling process. From Table 3, it can be obviously found that the $\beta$-O-4 was the major linkage in all MWL samples, which is in agreement with the report of Kishimoto et al. (2006) that the frequency of $\beta$-O-4 linkage accounts for $40 \%-65 \%$ in the lignin biomacromolecule.

Generally, the value of S/G ratio is the key index to evaluate which kind of lignin can be easily isolated during ball milling process (Wen et al., 2015; Jiang et al., 2017a). Table 3 shows that there was no significant difference in the S/G ratio for the MWL samples from different milling time for the bamboo residues $(\sim 1.0)$ and poplar sawdust $(\sim 0.8)$, while MWL samples from

TABLE 3 | The amount of lignin substructures and S/G ratio of prepared MWL samples from biomass at different milling times.

Biomass

Milling time (h)
Amount of lignin substructures (100Ar)

$\beta-0-4$ (A)

Bamboo residues

Poplar sawdust

Larch sawdust

\section{$\beta-\beta$ (B)}

12.7

15.6

16.2

10.7

14.7

25.1

15.2

16.6

16.2

68.2
61.3
60.1
58.7
56.4
55.5
66.0
60.9
59.4

68.2

61.3

56.4

55.5

66.0

59.4
S/G ratio

$\beta-5$ (C)

$\begin{array}{cc}4.1 & 1.0 \\ 4.8 & 1.1 \\ 4.1 & 1.1 \\ 5.9 & 0.8 \\ 8.3 & 0.8 \\ 5.4 & 0.7 \\ 7.5 & / \\ 6.6 & / \\ 4.2 & /\end{array}$

Note. a: $S / G=\left(I_{S 2, d} / 2\right) / I_{G 2}$. 
TABLE 4 | The contents of functional groups in MWL samples from different biomass $(\mathrm{mmol} / \mathrm{g})$.

\begin{tabular}{|c|c|c|c|c|c|c|}
\hline & \multirow{2}{*}{$\begin{array}{l}\text { Milling time } \\
\text { (h) }\end{array}$} & \multirow[t]{2}{*}{ Aliphatic hydroxyl } & \multicolumn{2}{|c|}{ Phenolic hydroxyl } & \multirow{2}{*}{$\begin{array}{c}\text { Total phenolic } \\
\text { hydroxyl }\end{array}$} & \multirow[t]{2}{*}{ COOH } \\
\hline & & & Condensed phenolic $\mathrm{OH}$ & Noncondensed phenolic OH & & \\
\hline \multirow[t]{3}{*}{ Bamboo residues } & 3 & 1.8 & 1.6 & 1.5 & 3.1 & 0.3 \\
\hline & 5 & 2.1 & 1.6 & 2.4 & 4.0 & 0.3 \\
\hline & 7 & 2.2 & 1.8 & 2.4 & 4.2 & 0.5 \\
\hline \multirow[t]{3}{*}{ Poplar sawdust } & 3 & 1.8 & 1.6 & 2.1 & 3.7 & 0.5 \\
\hline & 5 & 2.6 & 1.5 & 2.6 & 4.1 & 0.6 \\
\hline & 7 & 2.9 & 1.6 & 2.6 & 4.2 & 0.5 \\
\hline \multirow[t]{3}{*}{ Larch sawdust } & 3 & 1.9 & 1.8 & 1.8 & 3.6 & 0.4 \\
\hline & 5 & 1.9 & 1.9 & 2.1 & 4.0 & 0.4 \\
\hline & 7 & 2.2 & 1.9 & 2.2 & 4.1 & 0.5 \\
\hline
\end{tabular}

bamboo residues possessed a higher $S / G$ ratio than that of poplar sawdust, indicating that the S-type lignin in poplar sawdust is more recalcitrant to be isolated. In the work of Capanema et al. (2015), they found that the obtained lignin from hardwood with a greater content of S-type unit shows a tendency to endow lignin with a higher amount of $\beta-\mathrm{O}-4$ linkage. Hence, it can be speculated that the higher value of $\mathrm{S} / \mathrm{G}$ ratio in MWL samples from bamboo residues might be the reason why they had the highest amount of $\beta-\mathrm{O}-4$ than that of MWL samples from poplar sawdust. Based on the aforementioned results, it can be seen that increasing ball milling time indeed degraded the $\beta-\mathrm{O}-4$ in the obtained MWL sample, while it showed little effect on the ratio of lignin unit type in the MWL biomacromolecule.

\section{Effect of different milling time on the functional group of prepared milled wood lignin samples}

Generally, the degradation of substructures $(\beta-\mathrm{O}-4, \beta-\beta, \beta-1$, et al.) of lignin inevitably affected the content of the functional group of the prepared lignin (Shao et al., 2020). Hence, quantitative ${ }^{31} \mathrm{P}$ NMR technology was performed to analyze the changes in the functional group (aliphatic hydroxyl and phenolic hydroxyl) of the prepared MWL samples in bamboo residues, poplar sawdust, and larch sawdust by different milling times. From Table 4, it can be seen that prolonging the milling time resulted in the prepared MWL samples with the increased contents of aliphatic hydroxyl and phenolic hydroxyl groups. The reason for these results can be explained by the increased degradation degree of $\beta$-O-4, which can result in the lignin with enhanced amount of hydroxyl groups. In addition, it is found that increasing the ball milling time from 5 to $7 \mathrm{~h}$ did not seriously affect the contents of aliphatic hydroxyl and total phenolic hydroxyl groups in all MWL samples. These results were similar to the work of Wang R. et al. (2021) wherein increasing ball milling time showed a small effect on the structure of lignin during isolation process. It should be pointed out that there was no significant difference in the contents of functional groups in MWL samples from different biomasses treating by the same ball milling time.

\section{CONCLUSION}

In this work, ball milling with different times (3, 5, and $7 \mathrm{~h}$ ) using $\mathrm{ZrO}_{2}$ bowl with $\mathrm{ZrO}_{2}$ balls $(\Phi \mathrm{A}=1 \mathrm{~cm})$ at $600 \mathrm{rpm}$ was carried out to isolate the MWL samples in poplar sawdust, larch sawdust, and bamboo residues. It is found that milling time with 3 and $7 \mathrm{~h}$ was sufficient to isolate the representative lignin with yields over $30 \%$ for bamboo residues and poplar sawdust, respectively, while more than $7 \mathrm{~h}$ should be carried out to isolate the representative lignin in larch sawdust. During the ball milling process with prolonged time, the prepared MWL possessed a smaller substructure of $\beta-\mathrm{O}-4$, lower molecular weight, and higher content of hydroxyl groups, which was due to the occurred degradation. To prepare the representative MWL in different biomass, not only the ball milling time should be considered; it also should be focused on the degradation degree of the substructure of lignin.

\section{DATA AVAILABILITY STATEMENT}

The original contributions presented in the study are included in the article/Supplementary Material. Further inquiries can be directed to the corresponding author.

\section{AUTHOR CONTRIBUTIONS}

GY isolated the lignin and wrote the manuscript. XA performed the structural analysis of MWL samples by NMR technology. SY proposed the idea and revised the manuscript.

\section{FUNDING}

This work was supported by the Natural Science Research of Jiangsu Higher Education Institutions of China (19KJB220005), the Innovation Fund for Young Scholars of Nanjing Forestry University (CX2017004). 


\section{REFERENCES}

Azhar, S. S., Suhardy, D., Kasim, F. H., and Nazry Saleh, M. (2007). Isolation and Characterization of Pulp from Sugarcane Bagasse and rice Straw. J. Nucl. Relat. Tech. 4, 109-113. doi:10.1016/j.bej.2007.06.005

Bjorkman, A. (1956). Studies on Finely Divided wood. Part I. Extraction of Lignin with Neutral Solvents. Sven. Papperstidning. 59, 477-485.

Capanema, E. A., Balakshin, M. Y., and Kadla, J. F. (2004). A Comprehensive Approach for Quantitative Lignin Characterization by NMR Spectroscopy. J. Agric. Food Chem. 52, 1850-1860. doi:10.1021/jf035282b

Capanema, E., Balakshin, M., Katahira, R., Chang, H.-m., and Jameel, H. (2015). How Well Do MWL and CEL Preparations Represent the Whole Hardwood Lignin? J. Wood Chem. Tech. 35 (1), 17-26. doi:10.1080/02773813.2014.892993

Chen, X., Li, H., Sun, S., Cao, X., and Sun, R. (2018). Co-production of Oligosaccharides and Fermentable Sugar from Wheat Straw by Hydrothermal Pretreatment Combined with Alkaline Ethanol Extraction. Ind. Crops Prod. 111, 78-85. doi:10.1016/j.indcrop.2017.10.014

Dong, H., Zheng, L., Yu, P., Jiang, Q., Wu, Y., Huang, C., et al. (2020). Characterization and Application of Lignin-Carbohydrate Complexes from Lignocellulosic Materials as Antioxidants for Scavenging In Vitro and In Vivo Reactive Oxygen Species. ACS Sust. Chem. Eng. 8 (1), 256-266. doi:10.1021/ acssuschemeng.9b05290

Gu, J., Guo, M., Zheng, L., Yin, X., Zhou, L., Fan, D., et al. (2021). Protective Effects of Lignin-Carbohydrate Complexes from Wheat Stalk against Bisphenol a Neurotoxicity in Zebrafish via Oxidative Stress. Antioxidants 10 (10), 1640. doi:10.3390/antiox10101640

Guerra, A., Filpponen, I., Lucia, L. A., Saquing, C., Baumberger, S., and Argyropoulos, D. S. (2006). Toward a Better Understanding of the Lignin Isolation Process from wood. J. Agric. Food Chem. 54, 5939-5947. doi:10.1021/ jf060722v

Halleraker, H. V., and Barth, T. (2020). Quantitative NMR Analysis of the Aqueous Phase from Hydrothermal Liquefaction of Lignin. J. Anal. Appl. Pyrolysis 151, 104919. doi:10.1016/j.jaap.2020.104919

Henriksson, G. (2017). What Are the Biological Functions of Lignin and its Complexation with Carbohydrates? Nord Pulp Papres J. 32 (4), 527-541. doi:10.3183/NPPRJ-2017-32-04-p527-541

Himmel, M. E., Ding, S.-Y., Johnson, D. K., Adney, W. S., Nimlos, M. R., Brady, J. W., et al. (2007). Biomass Recalcitrance: Engineering Plants and Enzymes for Biofuels Production. Science 315, 804-807. doi:10.1126/science.1137016

Hu, Y. Y., Yan, B. W., Chen, Z. S., Wang, L., Tang, W., and Huang, C. X. (2021). Recent Technologies for the Extraction and Separation of Polyphenols in Different Plants: A Review. J. Renew. Mater. doi:10.32604/jrm.2022.018811

Huang, C., Dong, H., Zhang, Z., Bian, H., and Yong, Q. (2020). Procuring the Nano-Scale Lignin in Prehydrolyzate as Ingredient to Prepare Cellulose Nanofibril Composite Film with Multiple Functions. Cellulose 27 (16), 9355-9370. doi:10.1007/s10570-020-03427-9

Huang, C., He, J., Du, L., Min, D., and Yong, Q. (2016a). Structural Characterization of the Lignins from the green and Yellow Bamboo of Bamboo Culm (Phyllostachys Pubescens). J. Wood Chem. Tech. 36 (3), 157-172. doi:10.1080/02773813.2015.1104544

Huang, C., He, J., Narron, R., Wang, Y., and Yong, Q. (2017b). Characterization of Kraft Lignin Fractions Obtained by Sequential Ultrafiltration and Their Potential Application as a Biobased Component in Blends with Polyethylene. ACS Sust. Chem. Eng. 5, 11770-11779. doi:10.1021/ acssuschemeng.7b03415

Huang, C., Jeuck, B., Du, J., Yong, Q., Chang, H.-m., Jameel, H., et al. (2016b). Novel Process for the Coproduction of Xylo-Oligosaccharides, Fermentable Sugars, and Lignosulfonates from Hardwood. Bioresour. Tech. 219, 600-607. doi:10.1016/j.biortech.2016.08.051

Huang, C., Jiang, X., Shen, X., Hu, J., Tang, W., Wu, X., et al. (2022). Lignin-enzyme Interaction: A Roadblock for Efficient Enzymatic Hydrolysis of Lignocellulosics. Renew. Sust. Energ. Rev. 154, 111822. doi:10.1016/ j.rser.2021.111822

Huang, C., Lai, C., Wu, X., Huang, Y., He, J., Huang, C., et al. (2017a). An Integrated Process to Produce Bio-Ethanol and Xylooligosaccharides Rich in Xylobiose and Xylotriose from High Ash Content Waste Wheat Straw. Bioresour. Tech. 241, 228-235. doi:10.1016/j.biortech.2017.05.109
Huang, C., Ma, J., Zhang, W., Huang, G., and Yong, Q. (2018). Preparation of Lignosulfonates from Biorefinery Lignins by Sulfomethylation and Their Application as a Water Reducer for concrete. Polymers 10 (8), 841. doi:10.3390/polym 10080841

Huang, F., Singh, P. M., and Ragauskas, A. J. (2011). Characterization of Milled wood Lignin (MWL) in Loblolly pine Stem wood, Residue, and Bark. J. Agric. Food Chem. 59 (24), 12910-12916. doi:10.1021/jf202701b

Hussin, M. H., Rahim, A. A., Mohamad Ibrahim, M. N., Yemloul, M., Perrin, D., and Brosse, N. (2014). Investigation on the Structure and Antioxidant Properties of Modified Lignin Obtained by Different Combinative Processes of Oil palm Fronds (OPF) Biomass. Ind. Crops Prod. 52, 544-551. doi:10.1016/ j.indcrop.2013.11.026

Ibrahim, M. N. M., Rosli, W. D. W., and Chuah, S. B. (2012). Monitoring Quality of Soda Black Liquor of Oil palm Empty Fruit bunch Fibers in Terms of Storage Time and Temperature. J. Teknol. 42, 21-28. doi:10.11113/jt.v42.744

Jiang, B., Cao, T., Gu, F., Wu, W., and Jin, Y. (2017a). Comparison of the Structural Characteristics of Cellulolytic Enzyme Lignin Preparations Isolated from Wheat Straw Stem and Leaf. ACS Sust. Chem. Eng. 5 (1), 342-349. doi:10.1021/acssuschemeng.6b01710

Jiang, X., Abbati de Assis, C., Kollman, M., Sun, R., Jameel, H., Chang, H.-m., et al. (2020). Lignin Fractionation from Laboratory to Commercialization: Chemistry, Scalability and Techno-Economic Analysis. Green. Chem. 22 (21), 7448-7459. doi:10.1039/d0gc02960b

Jiang, X., Savithri, D., Du, X., Pawar, S., Jameel, H., Chang, H.-m., et al. (2017b). Fractionation and Characterization of Kraft Lignin by Sequential Precipitation with Various Organic Solvents. ACS Sust. Chem. Eng. 5, 835-842. doi:10.1021/ acssuschemeng.6b02174

Kim, J.-Y., Shin, E.-J., Eom, I.-Y., Won, K., Kim, Y. H., Choi, D., et al. (2011). Structural Features of Lignin Macromolecules Extracted with Ionic Liquid from poplar wood. Bioresour. Tech. 102 (19), 9020-9025. doi:10.1016/j.biortech.2011.07.081

Kishimoto, T., Uraki, Y., and Ubukata, M. (2006). Chemical Synthesis of $\beta-O-4$ Type Artificial Lignin. Org. Biomol. Chem. 4, 1343-1347. doi:10.1039/ B518005H

Lai, C., Jia, Y., Wang, J., Wang, R., Zhang, Q., Chen, L., et al. (2019). Co-production of Xylooligosaccharides and Fermentable Sugars from poplar through Acetic Acid Pretreatment Followed by Poly (Ethylene Glycol) Ether Assisted Alkali Treatment. Bioresour. Tech. 288, 121569. doi:10.1016/j.biortech.2019.121569

Lange, H., Decina, S., and Crestini, C. (2013). Oxidative Upgrade of Lignin - Recent Routes Reviewed. Eur. Polym. J. 49, 1151-1173. doi:10.1016/ j.eurpolymj.2013.03.002

Liao, J. J., Latif, N. H. A., Trache, D., Brosse, N., and Hussin, M. H. (2020). Current Advancement on the Isolation, Characterization and Application of Lignin. Int. J. Biol. Macromolecules 162, 985-1024. doi:10.1016/j.ijbiomac.2020.06.168

Lin, W., Yang, J., Zheng, Y., Huang, C., and Yong, Q. (2021). Understanding the Effects of Different Residual Lignin Fractions in Acid-Pretreated Bamboo Residues on its Enzymatic Digestibility. Biotechnol. Biofuels. 14 (1), 143. doi:10.1186/s13068-021-01994-y

Liu, H., Xu, T., Liu, K., Zhang, M., Liu, W., Li, H., et al. (2021b). Lignin-based Electrodes for Energy Storage Application. Ind. Crops Prod. 165, 113425. doi:10.1016/j.indcrop.2021.113425

Liu, K., Du, H., Zheng, T., Liu, W., Zhang, M., Liu, H., et al. (2021a). Lignincontaining Cellulose Nanomaterials: Preparation and Applications. Green. Chem. doi:10.1039/D1GC02841C

Luo, Y., Li, Y., Cao, L., Zhu, J., Deng, B., Hou, Y., et al. (2021). High Efficiency and Clean Separation of eucalyptus Components by Glycolic Acid Pretreatment. Bioresour. Tech. 341, 125757. doi:10.1016/j.biortech.2021.125757

Luykx, D. M. A. M., Peters, R. J. B., Van Ruth, S. M., and Bouwmeester, H. (2008). A Review of Analytical Methods for the Identification and Characterization of Nano Delivery Systems in Food. J. Agric. Food Chem. 56, 8231-8247. doi:10.1021/jf8013926

Martín-Sampedro, R., Santos, J. I., Fillat, Ú., Wicklein, B., Eugenio, M. E., and Ibarra, D. (2019). Characterization of Lignins from Populus alba L. Generated as By-Products in Different Transformation Processes: Kraft Pulping, Organosolv and Acid Hydrolysis. Int. J. Biol. Macromolecules 126, 18-29. doi:10.1016/j.ijbiomac.2018.12.158

Pan, X. -J. (2008). Role of Functional Groups in Lignin Inhibition of Enzymatic Hydrolysis of Cellulose to Glucose. J. Biobased Mater. Bio. 2 (1), 25-32. doi:10.1166/jbmb.2008.005 
Pei, W., Shang, W., LiangJiang, C. X., Jiang, X., Huang, C., and Yong, Q. (2020). Using Lignin as the Precursor to Synthesize Fe3O4@lignin Composite for Preparing Electromagnetic Wave Absorbing Lignin-Phenol-Formaldehyde Adhesive. Ind. Crops Prod. 154, 112638. doi:10.1016/j.indcrop.2020.112638

Ragauskas, A. J., Williams, C. K., Davison, B. H., Britovsek, G., Cairney, J., Eckert, C. A., et al. (2006). The Path Forward for Biofuels and Biomaterials. Science 311, 484-489. doi:10.1126/science.1114736

Shao, Z., Fu, Y., Wang, P., Zhang, Y., Qin, M., Li, X., et al. (2020). Modification of the aspen Lignin Structure during Integrated Fractionation Process of Autohydrolysis and Formic Acid Delignification. Int. J. Biol. Macromolecules 165, 1727-1737. doi:10.1016/j.ijbiomac.2020.10.026

Sluiter, A., Hames, B., Ruiz, R., Scarlata, C., Sluiter, J., and Templeton, D. (2011). Determination of Structural Carbohydrates and Lignin in Biomass. National renewable energy laboratory Anal.Procedure, Technical Report NREL/TP-510-42618.

Sun, Y.-C., Xu, J.-K., Xu, F., and Sun, R.-C. (2013). Efficient Separation and Physico-Chemical Characterization of Lignin from eucalyptus Using Ionic Liquid-Organic Solvent and Alkaline Ethanol Solvent. Ind. Crops Prod. 47, 277-285. doi:10.1016/j.indcrop.2013.03.025

Tang, W., Wu, X., Huang, C., Ling, Z., Lai, C., and Yong, Q. (2021). Revealing the Influence of Metallic Chlorides Pretreatment on Chemical Structures of Lignin and Enzymatic Hydrolysis of Waste Wheat Straw. Bioresour. Tech. 342, 125983. doi:10.1016/j.biortech.2021.125983

Wang, R., Zheng, L., Xu, Q., Xu, L., Wang, D., Li, J., et al. (2021). Unveiling the Structural Properties of Water-Soluble Lignin from Gramineous Biomass by Autohydrolysis and its Functionality as a Bioactivator (Anti-inflammatory and Antioxidative). Int. J. Biol. Macromolecules 191, 1087-1095. doi:10.1016/j.ijbiomac.2021.09.124

Wang, Y., Liu, W., Zhang, L., and Hou, Q. (2019). Characterization and Comparison of Lignin Derived from Corncob Residues to Better Understand its Potential Applications. Int. J. Biol. Macromolecules 134, 20-27. doi:10.1016/j.ijbiomac.2019.05.013

Wang, Z., Zhu, X., and Deuss, P. J. (2021). The Effect of ball Milling on Birch, pine, Reed, walnut Shell Enzymatic Hydrolysis Recalcitrance and the Structure of the Isolated Residual Enzyme Lignin. Ind. Crops Prod. 167, 113493. doi:10.1016/ j.indcrop.2021.113493

Wen, J.-L., Sun, S.-L., Yuan, T.-Q., and Sun, R.-C. (2015). Structural Elucidation of Whole Lignin from eucalyptus Based on Preswelling and Enzymatic Hydrolysis. Green. Chem. 17 (3), 1589-1596. doi:10.1039/c4gc01889c

Xu, Q. H., Wang, Y. P., Qin, M. H., Fu, Y. J., Li, Z. Q., Zhang, F. S., et al. (2011). Fiber Surface Characterization of Old Newsprint Pulp Deinked by Combining Hemicellulase with Laccase-Mediator System. Bioresour. Tech. 102, 6536-6540. doi:10.1016/j.biortech.2011.03.051

Yang, D., Qiu, X., Zhou, M., and Lou, H. (2007). Properties of Sodium Lignosulfonate as Dispersant of Coal Water Slurry. Energ. Convers. Manage. 48, 2433-2438. doi:10.1039/b915105b10.1016/j.enconman.2007.04.007

Yuan, T.-Q., Xu, F., and Sun, R.-C. (2013). Role of Lignin in a Biorefinery: Separation Characterization and Valorization. J. Chem. Technol. Biotechnol. 88, 346-352. doi:10.1002/jctb.3996
Yuan, Z., Cheng, S., Leitch, M., and Xu, C. (2010). Hydrolytic Degradation of Alkaline Lignin in Hot-Compressed Water and Ethanol. Bioresour. Tech. 101 (23), 9308-9313. doi:10.1016/j.biortech.2010.06.140

Yun, J., Wei, L., Li, W., Gong, D., Qin, H., Feng, X., et al. (2021). Isolating High Antimicrobial Ability Lignin from Bamboo Kraft Lignin by Organosolv Fractionation. Front. Bioeng. Biotechnol. 9, 683796. doi:10.3389/ fbioe.2021.683796

Zhang, A., Lu, F., Liu, C., and Sun, R.-C. (2010). Isolation and Characterization of Lignins from eucalyptus Tereticornis (12ABL). J. Agric. Food Chem. 58, 11287-11293. doi:10.1021/jf103354x

Zhang, Q., Cheng, L., Ma, X., Zhou, X., and Xu, Y. (2021). Revalorization of sunflower Stalk Pith as Feedstock for the Coproduction of Pectin and Glucose Using a Two-step Dilute Acid Pretreatment Process. Biotechnol. Biofuels. 14 (1), 194. doi:10.1186/s13068-021-02045-2

Zhao, J., Zhang, X., Zhou, X., and Xu, Y. (2021a). Selective Production of Xylooligosaccharides by Xylan Hydrolysis Using a Novel Recyclable and Separable Furoic Acid. Front. Bioeng. Biotechnol. 9, 660266. doi:10.3389/ fbioe.2021.660266

Zhao, X., Meng, X., Ragauskas, A. J., Lai, C., Ling, Z., Huang, C., et al. (2021b). Unlocking the Secret of Lignin-Enzyme Interactions: Recent Advances in Developing State-Of-The-Art Analytical Techniques. Biotechnol. Adv., 107830. doi:10.1016/j.biotechadv.2021.107830

Zheng, L., Lu, G., Pei, W., Yan, W., Li, Y., Zhang, L., et al. (2021a). Understanding the Relationship between the Structural Properties of Lignin and Their Biological Activities. Int. J. Biol. Macromolecules 190, 291-300. doi:10.1016/ j.ijbiomac.2021.08.168

Zheng, L., Yu, P., Zhang, Y., Wang, P., Yan, W., Guo, B., et al. (2021b). Evaluating the Bio-Application of Biomacromolecule of Lignin-Carbohydrate Complexes (LCC) from Wheat Straw in Bone Metabolism via ROS Scavenging. Int. J. Biol. Macromolecules 176, 13-25. doi:10.1016/j.ijbiomac.2021.01.103

Conflict of Interest: The authors declare that the research was conducted in the absence of any commercial or financial relationships that could be construed as a potential conflict of interest.

Publisher's Note: All claims expressed in this article are solely those of the authors and do not necessarily represent those of their affiliated organizations, or those of the publisher, the editors, and the reviewers. Any product that may be evaluated in this article, or claim that may be made by its manufacturer, is not guaranteed or endorsed by the publisher.

Copyright (c) 2021 Yang, An and Yang. This is an open-access article distributed under the terms of the Creative Commons Attribution License (CC BY). The use, distribution or reproduction in other forums is permitted, provided the original author(s) and the copyright owner(s) are credited and that the original publication in this journal is cited, in accordance with accepted academic practice. No use, distribution or reproduction is permitted which does not comply with these terms. 